\title{
Relationships between retinal break locations and the shapes of the detachments
}

This article was published in the following Dove Press journal:

Clinical Ophthalmology

\author{
Izumi Yoshida' \\ Tomoaki Shiba ${ }^{2}$ \\ Yuichi Hori' \\ Takatoshi Maeno² \\ 'Department of Ophthalmology, Toho \\ University Sakura Medical Center, \\ Chiba, Sakura, Japan; ${ }^{2}$ Department \\ of Ophthalmology, Toho University \\ Omori Medical Center, Tokyo, Japan
}

Correspondence: Izumi Yoshida Department of Ophthalmology, Toho University Sakura Medical Center, 564-I Shimoshizu, Chiba, Sakura 285-874I, Japan

$\mathrm{Tel}+8 \mathrm{I} 4346288 \mathrm{I}$ I

Fax +8I 434628820

Email izumi.yoshida@med.toho-u.ac.jp
Purpose: Detecting primary breaks and confirming detachment preoperatively are important. Lincoff stated that retinal detachments progress according to gravity; his law has become popular. We evaluated Lincoff's law with a slight modification to determine whether it remains suitable for present cases independent of refractive error and previous cataract surgery.

Patients and methods: Group 1 included superior region detachments not exceeding the 12 o'clock midline; the original break was within $11 / 2$ clock hours of the highest detachment border. Group 2 included shallow inferior detachment; the original break corresponded to the more spread side of the 6 o'clock midline. Group 3 detachments were beyond 12 o'clock; the original break was within a triangle with a 12 o'clock apex (A) or within 1 1/2 hours of 12 o'clock (B); (A) and (B) were stated in the original report. Another five classifications were applied for small numbers of detachments. Consecutive initial rhegmatogenous retinal detachment surgery patients were included; medical records and detachment charts were examined. Eyes were classified into categories and rates were calculated. Eyes that had never undergone previous cataract surgery besides those in which the macula remained attached were divided into groups at a -6 D cutoff (Groups 1, 2, and 3[B]); we compared groups in each category. We compared phakic eyes, pseudophakic eyes, and eyes ruptured at the posterior capsule (Groups 1, 2, and 3[B]).

Results: Finally, 747 eyes were categorized. In Groups 1, 2, 3(A), and 3(B), corresponding rates were $92,86,70$, and $89 \%$, respectively. Between the above and below $-6 \mathrm{D}$ groups, there was no significant difference in rate in any category. There were no significant differences between phakic, pseudophakic, and ruptured eyes.

Conclusion: Lincoff's law was suitable for the present cases and independent of refractive error and previous cataract surgery.

Keywords: rhegmatogenous retinal detachment, retinal break locations, shapes of detachments, refractive error, previous cataract surgery

\section{Introduction}

Retinal detachments can cause severe vision loss when they progress. The major treatments are scleral buckling ${ }^{1-5}$ and pars plana vitrectomy. ${ }^{6-8}$ Although outcomes were improved with the development of new procedures to perform both scleral buckling with a wide viewing system ${ }^{9,10}$ and micro-incision vitrectomy, ${ }^{11-13}$ it is still very important to detect the primary break and confirm the courter of detachment before surgery. Lincoff et al stated the principle that retinal detachments progress according to gravity and the locations of breaks were evaluated from the shape of the detachment using 1,000 rhegmatogenous retinal detachments. ${ }^{14,15}$ Afterward, Ogino ${ }^{16}$ and Okinami et $\mathrm{al}^{17}$ reported that the lattice-hole detachment had a tendency to occur in the peripheral temporal inferior region of myopic eyes in young men and that horseshoe-shaped 
tears occurred in a more posterior temporal superior region in older men. Moreover, there were other reports about the characteristics of posterior tears with posterior vitreous detachments. ${ }^{18}$ However, Lincoff's law became the most popular classification and gained acceptance because it is versatile and directly useful for treatment. Except for an examination of 334 detachments by Yoshioka et a ${ }^{19}$ in 1972 and 441 detachments by Hanselmayer ${ }^{20}$ in 1972, there are few reports concerning the relationship between a simple break location and the detachment shape to the best of our knowledge.

Forty-seven years have passed since Lincoff's report. Moreover, we are interested in whether these rules are still suitable for present cases and Japanese cases with a high incidence of myopia. ${ }^{21}$ Furthermore, we examined two remaining issues. First, Lincoff provided two answers regarding frequent appearance region of breaks for detachments that intersect 12 o'clock. Second, the certain number and proportion of inferior bullous detachments were not referred. We evaluated Lincoff's law and traced his classifications and investigated these issues with minimum modifications.

\section{Modified categorization of detachment shapes in this study}

Details of the modified categorization of retinal detachment shapes based on Lincoff's rule are shown below. All our cases were classified into eight groups as follows: Group 1: detachments that occurred in the temporal or nasal superior region and did not exceed the 12 o'clock midline with the original break within $11 / 2$ clock hours of the highest border of the detachment (in Figures 1 and 2, the black regions show the corresponding patterns of breaks in this category and the gray regions show the shapes of the detachments with our original drawing according to Lincoff's schema from the original report); Group 2: shallow detachments that occurred in the inferior region with the original break corresponding to the more spread side of the 6 o'clock midline (Figure 3); and Group 3: detachments intersecting the 12 o'clock superior vertical midline shown in the schema from the original report (Figure 4). In Group 3, Lincoff mentioned that the original break should be within a triangle whose apex is at 12 o'clock and should intersect the equators shown in the schema for detachments beyond 12 o'clock from the original text in Group 3(A) (Figure 4); in addition, he restated that the original holes could be within $11 / 2$ hours of 12 o'clock in Group 3(B) (Figure 5) in the same text. Accordingly, we examined this category using both criteria. Moreover, in the original report from 1971, there were five other classifications. Along with these classifications, other cases

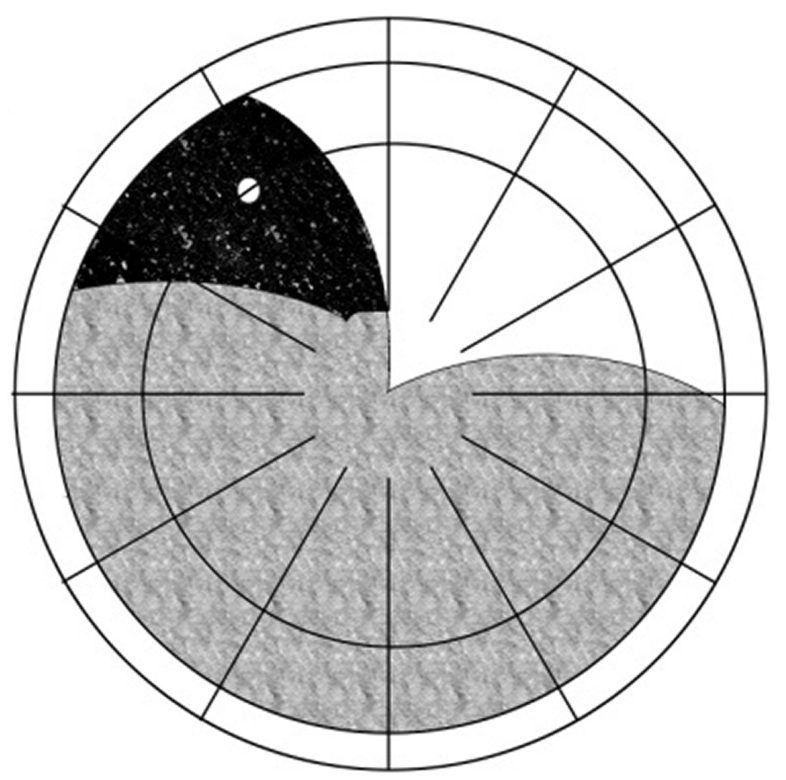

Figure I Group I: detachments that occurred in the temporal or nasal superior region and did not exceed 12 o'clock.

Notes: Gray regions show the shapes of detachments, and breaks are inside black regions or within I I/2 hours of the highest border of the detachment corresponding with Lincoff's law. White spot is one example for corresponding break location. We drew this schema to correspond with the same schema from the original text of Lincoff and Gieser. ${ }^{14}$

were classified into five more groups as follows: Group 4: symmetrical detachment occurring from the original break at 6 o'clock (Figure 6); Group 5: inferior bullous detachment with the original break in the superior region (Figure 7); Group 6: detachments across both the superior vertical and

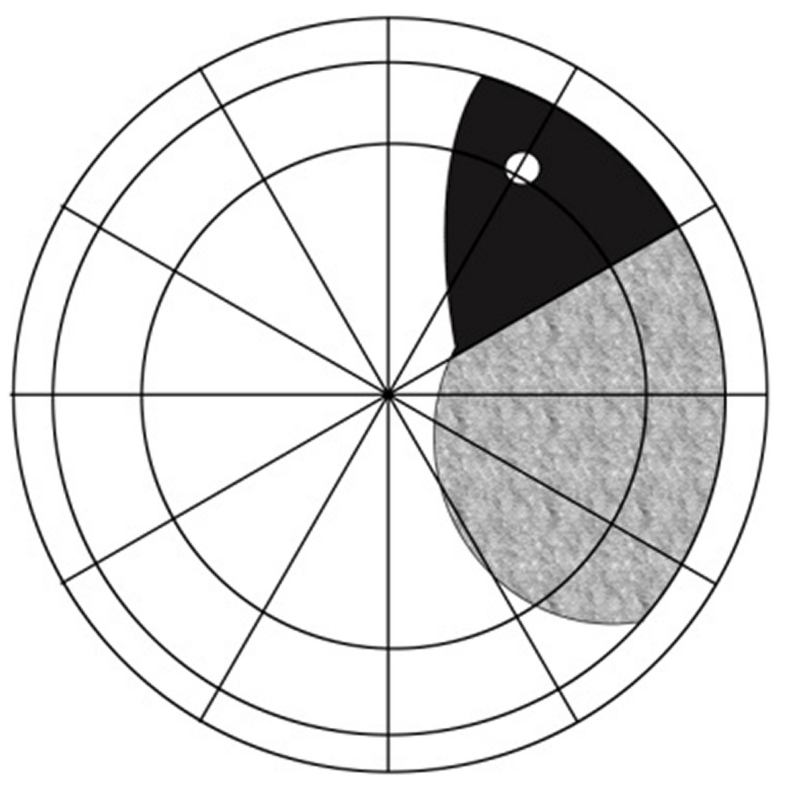

Figure 2 Superior temporal or nasal detachments that did not exceed the inferior vertical midline.

Notes: These detachments were included in Group I (see Figure I). The black regions show the corresponding patterns of breaks in this category, the gray regions show the shapes of the detachments with our original drawing according to data from Lincoff and Gieser. ${ }^{14}$ 


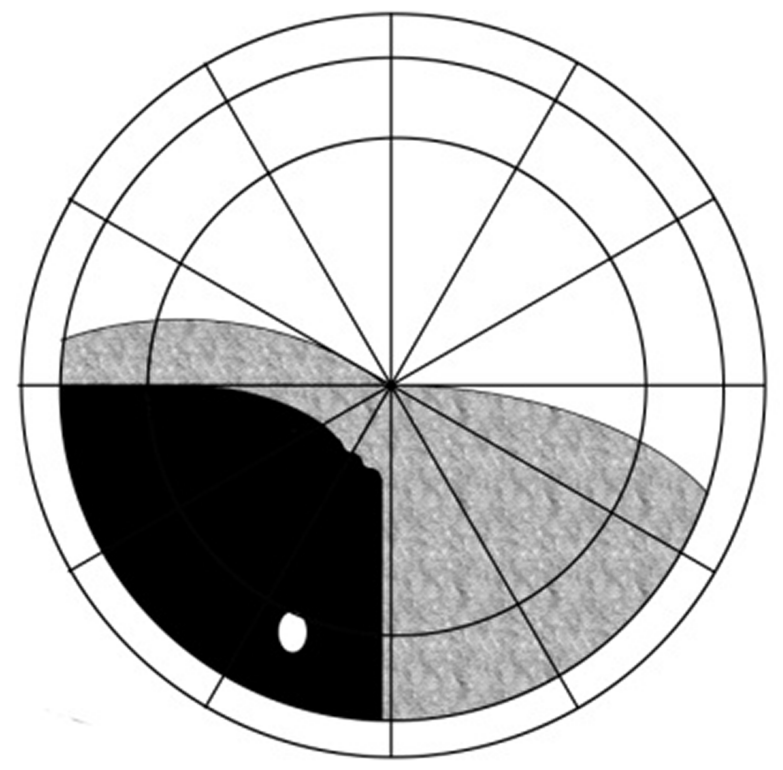

Figure 3 Group 2: shallow detachments that occurred in the inferior region. Notes: Gray regions show the shapes of detachments of this category, and breaks inside black regions are corresponding pattern with Lincoff's law. White spot is one example for corresponding break location. The breaks shown inside the black region and those corresponding to the more spread side at the 6 o'clock midline correspond with Lincoff's law. Data from Lincoff and Gieser. ${ }^{14}$

horizontal midlines with the original break on the side of the 12 o'clock meridian with the lower detachment (Figure 8); Group 7: almost total detachment except for a superior wedge-shaped attachment with the original break in the periphery near the highest border (Figure 9); and Group 8:

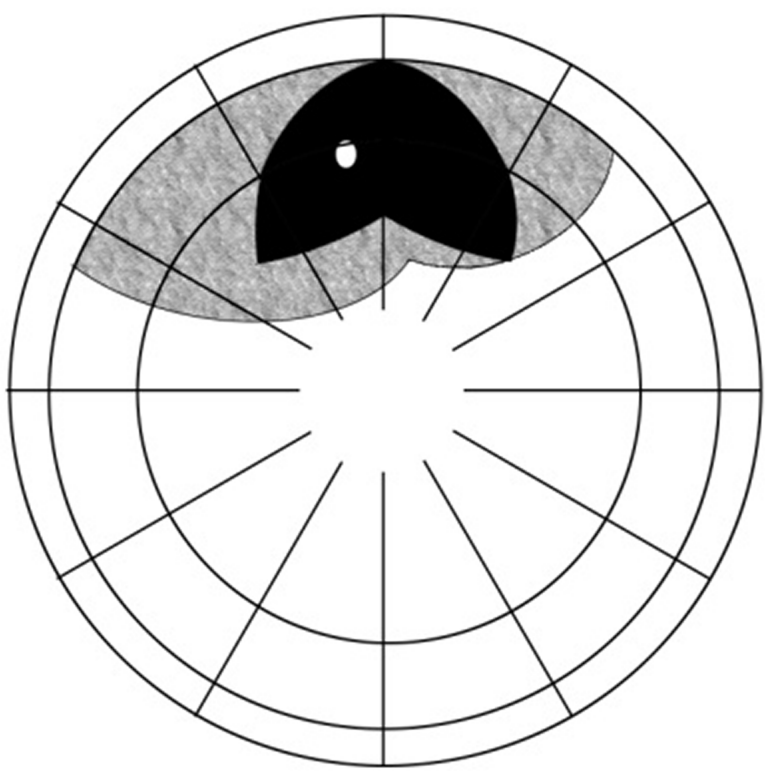

Figure 4 Group 3(A): detachments intersecting 12 o'clock.

Notes: The breaks are shown inside the black region or within the triangle whose apex is at 12 o'clock and intersecting the corresponding equators. Gray regions show the shapes of detachments of this category, and breaks inside black regions are corresponding pattern with Lincoff's law. White spot is one example for corresponding break location. Data from Lincoff and Gieser. ${ }^{14}$

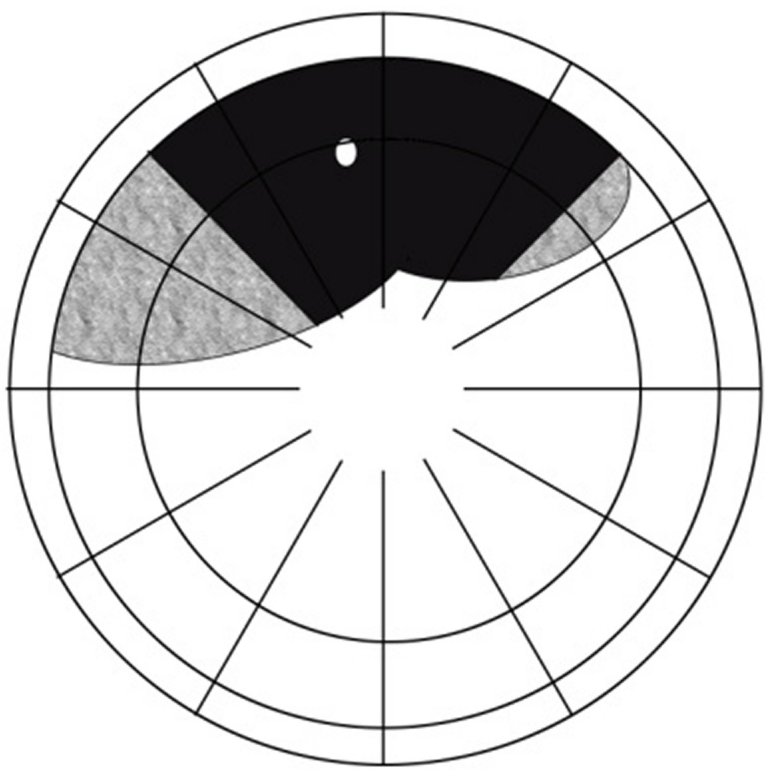

Figure 5 Group 3(B): this category is used to classify the same eyes as in Group 3 according to our different criteria for the corresponding pattern.

Notes: The breaks inside the black region or between 10:30 and 13:30 correspond. Gray regions show the shapes of detachments of this category, and breaks inside black regions are corresponding pattern with Lincoff's law. White spot is one example for corresponding break location. Data from Lincoff and Gieser. ${ }^{14}$

total detachment at or near 12 o'clock, particularly within $11 / 2$ hours of 12 o'clock (Figure 10).

Elsewhere, Lincoff avoided detachments "within a quadrant" that were too small for his law. In addition, macular hole detachments were rarely discussed.

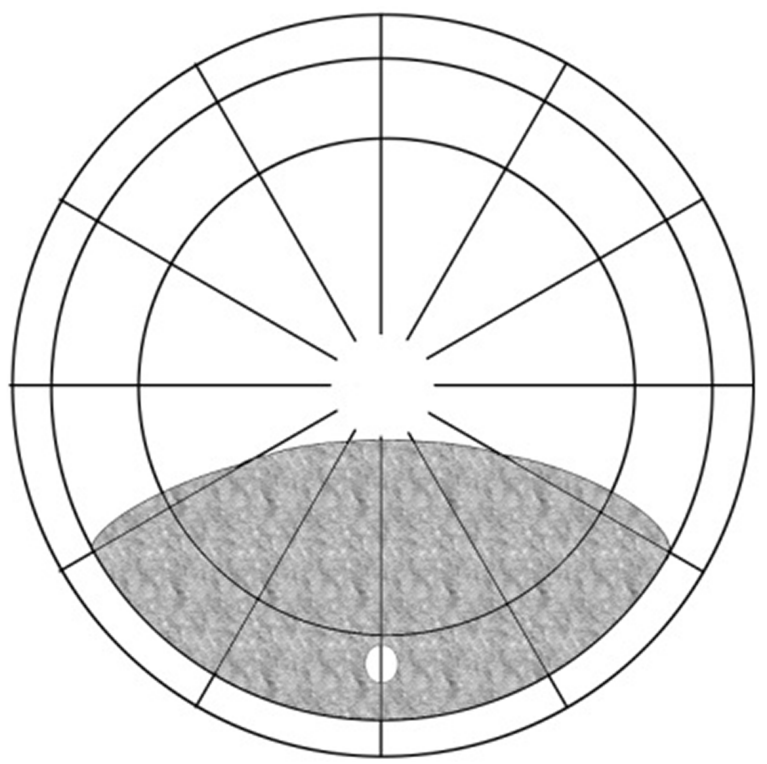

Figure 6 Group 4: symmetrical detachments.

Notes: Only breaks at 6 o'clock correspond. Gray regions show the shapes of detachments of this category, and white spot is one example for corresponding break location. Data from Lincoff and Gieser. ${ }^{14}$ 


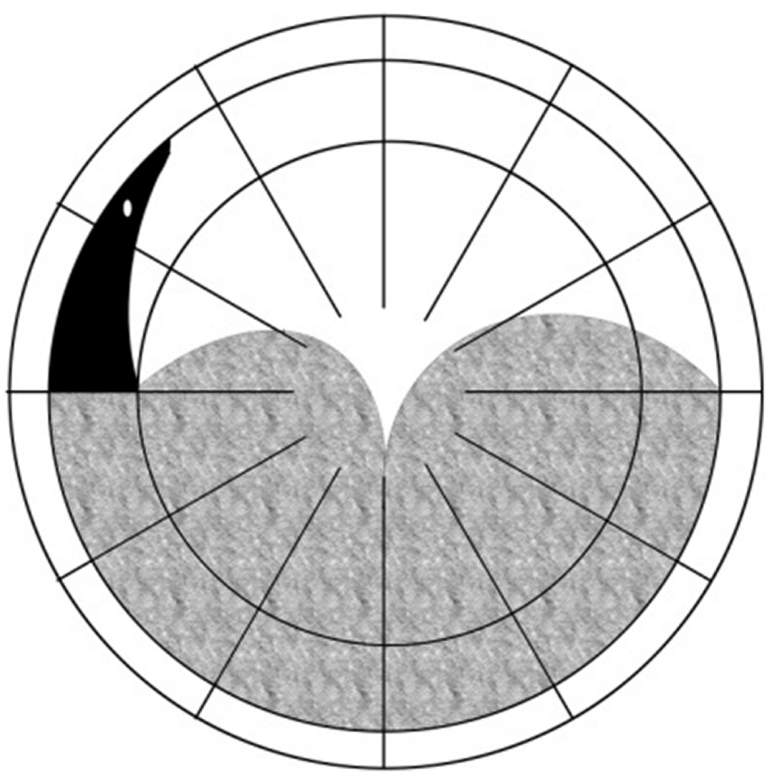

Figure 7 Group 5: inferior bullous detachments.

Notes: Breaks in the superior region correspond. Gray regions show the shapes of detachments of this category, and breaks inside black regions are corresponding pattern with Lincoff's law. White spot is one example for corresponding break location. Data from Lincoff and Gieser. ${ }^{14}$

\section{Materials and methods}

The Institutional Review Board of Toho University Sakura Medical Center approved this study. Consecutive patients who underwent initial operations for rhegmatogenous retinal detachments between January 2003 and December 2010 at

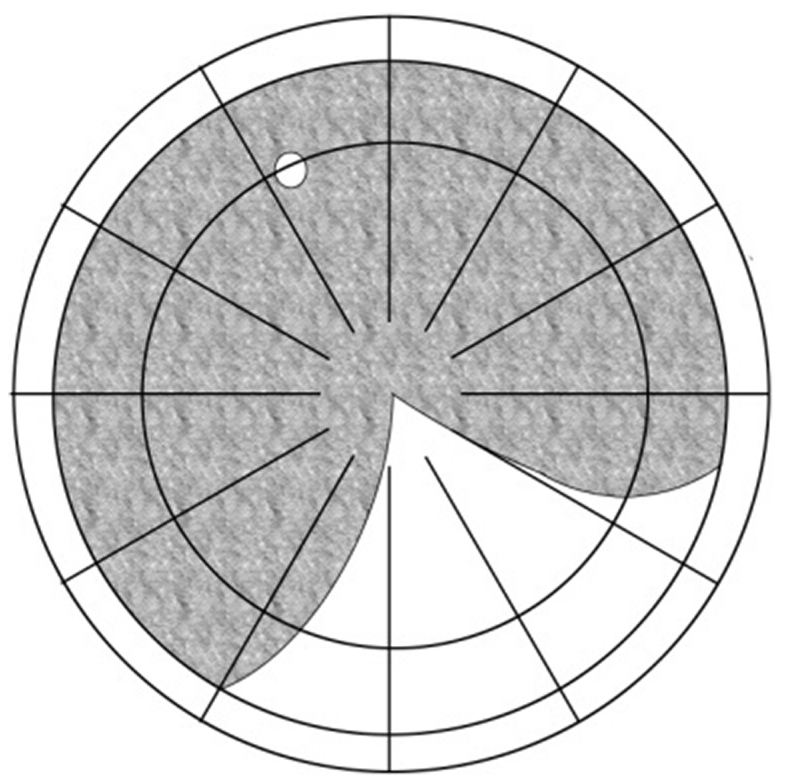

Figure 8 Group 6: detachments across both the superior vertical and horizontal midlines.

Notes: The breaks on the sides of the 12 o'clock meridian of the lower detachment correspond. Gray regions show the shapes of detachments of this category, and white spot is one example for corresponding break location. Data from Lincoff and Gieser. ${ }^{14}$

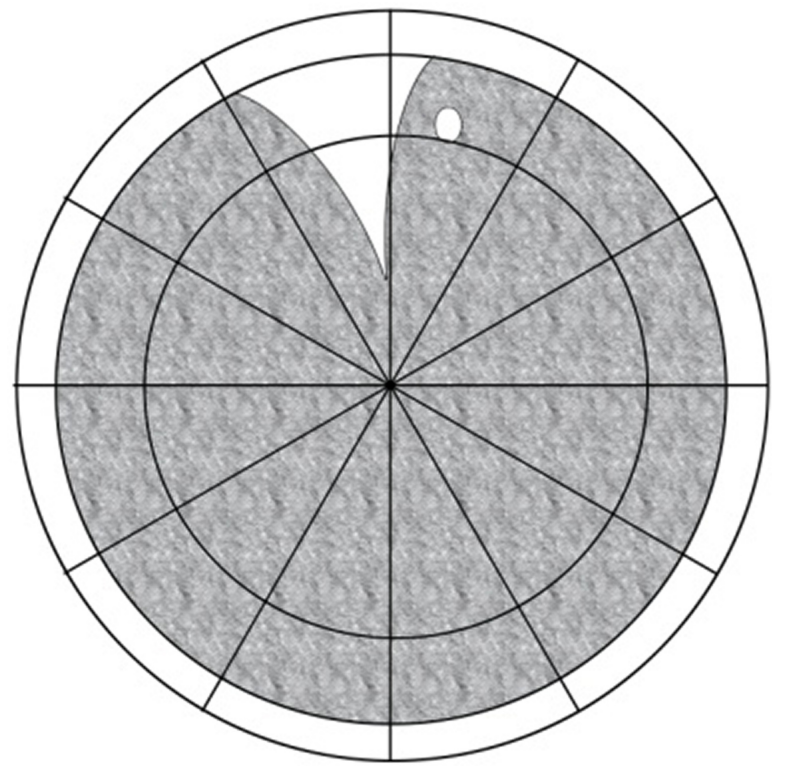

Figure 9 Group 7: almost total detachment except for a superior wedge-shaped attachment.

Notes: The breaks within the periphery near the highest border correspond. Gray regions show the shapes of detachments of this category, and white spot is one example for corresponding break location. Data from Lincoff and Gieser. ${ }^{14}$

Toho University Sakura Medical Center were analyzed for enrollment.

This study was retrospective in nature. Yoshida examined all medical records and detachment charts. The exclusion criteria were postoperative recurrent detachment, proliferative

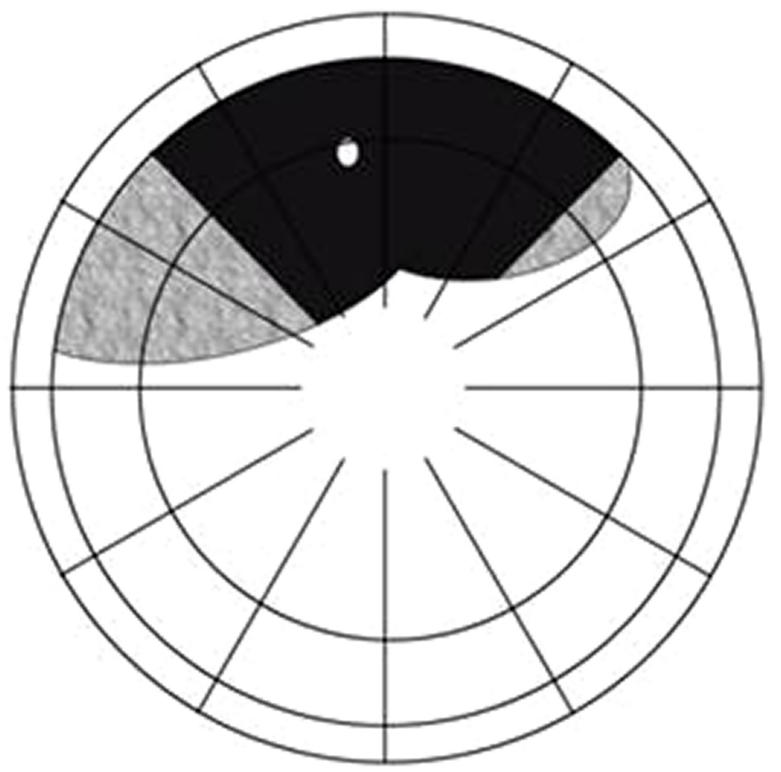

Figure 10 Group 8: total detachments.

Notes: The breaks between 10:30 and 13:30 correspond. Gray regions show the shapes of detachments of this category, and breaks inside black regions are corresponding pattern with Lincoff's law. White spot is one example for corresponding break location. Data from Lincoff and Gieser. ${ }^{14}$ 
diabetic retinopathy, grade $\mathrm{CP}$ and $\mathrm{AP}$ proliferative vitreoretinopathy according to the updated Retina Society classification, ${ }^{22}$ traumatic retinal detachments with globe rupture, and detachments previously treated with vitrectomy or photocoagulation for any retinal disease. Blunt trauma of the eyeball with retinal detachment and detachments after cataract surgery were included because they are generally considered to progress similar to usual retinal detachments. Macular holes were excluded from this study as Lincoff excluded from evaluation. Subjects were classified according to the eight stated categories, and the rates of break locations in corresponding regions were examined for all detachments in each category.

Furthermore, we examined the refractive errors of the patients. This study was retrospective; thus, an accurate refractive error was only identified for patients who had never undergone cataract surgery and whose macula had remained attached. In those patients, we evaluated the refractive errors measured using an RK-F1 Full Auto Ref-Keratometer (Canon, Tokyo, Japan) just before hospitalization. If patients had detached fovea but had previously visited our Medical Center, we evaluated the refractive errors at the last point before detachment. Eyes with previous laser refractive surgery were excluded from this evaluation. Especially, there was no record of axial lengths of patients who underwent buckling surgery without cataract surgery. We determined the median refractive errors in the three major categories of our classification, Groups 1, 2, and 3, and showed comparisons with the agreement rate between those eyes above or below $-6 \mathrm{D}$ in each category. In this procedure, for Group 3 , we adopted break criteria within $11 / 2$ hours of 12 o'clock (Group 3[B]) (Figure 5) and did not use the criteria within a triangle whose apex is at 12 o'clock and intersecting the equators (Group 3[A]) (Figure 4) to avoid confusion from complexity. As described in detail later, we consider this criterion more adequate than that of the triangle (Figure 4).

Additionally, we examined how many patients in our study underwent cataract surgery previously with or without posterior capsule rupture before rhegmatogenous detachment and the associated agreement rates in Groups 1, 2 , and $3(\mathrm{~B})$.

The study protocol was approved by the Institutional Review Board service at Toho University Sakura Medical Center (approval number no 2015-100). The procedures used conformed to the tenets of the Declaration of Helsinki. The design of the study was explained to patients using the Toho University Sakura Medical Center website in accordance with the guidelines for clinical research set out by the Japanese Ministry of Health, Labor, and Welfare. All patients provided written informed consent prior to the initiation of any treatment. Any and all private patient information was excluded from the database, and use of this anonymous information was approved by Institutional Review Board services without the need to seek another consent for use of data for research.

\section{Statistical analysis}

Difference between patient's age performed buckling surgery and performed vitrectomy with or without cataract surgery was analyzed using Welch's $t$-test. The proportional differences were analyzed using the chi-squared test with or without Yate's continuity correction and Fisher's exact test using Statcel 3 software ${ }^{\circledR}$, OMS (OMS Publishing Inc., Saitama, Japan) 2011. $P<0.05$ was adopted if comparisons were performed between two groups. $P<0.016$ was adopted if comparisons were performed between three groups.

\section{Results}

One thousand twenty-four eyes of 994 consecutive patients who underwent initial operations for rhegmatogenous retinal detachments were analyzed. The characteristics of the patients are shown in Table 1. Six hundred eighty-one eyes were treated with buckling surgery. Three hundred twentythree eyes were treated with vitrectomy with or without cataract surgery. The mean age was $50.6 \pm 27.7$ years, and patients who underwent buckling surgery were younger (mean age, $48.8 \pm 16.4$ years) than those who underwent vitrectomy with or without cataract surgery (mean age, 59.1 \pm 9.7 years $)(P<0.05)$.

As Lincoff avoided 216 cases with detachments that were too small (to a quadrant or less) and discussed the remaining 784 detachments, we excluded 125 cases with small detachments that did not cross both the vertical and horizontal lines. Moreover, because this study was retrospective, we could not determine the shape of the retinal detachment or the location of the original break from the surgical detachment chart or medical record in 127 cases. In six cases, two detachments occurred separately in one eye and, in 19 cases, detachments involved only a 3-o'clock or 9-o'clock original retinal break. These could not be classified into any categories according

Table I Subjects

\begin{tabular}{|c|c|c|c|}
\hline $\begin{array}{l}\text { First operative } \\
\text { method }\end{array}$ & & $\begin{array}{l}\text { Age } \\
\text { (years) }\end{array}$ & P-value \\
\hline Buckling & 681 eyes & $48.8 \pm 16.4$ & $<0.00001$ \\
\hline $\begin{array}{l}\text { Vitrectomy (with or } \\
\text { without cataract surgery) }\end{array}$ & 323 eyes & $59.1 \pm 9.7$ & \\
\hline Another procedure & 20 eyes & & \\
\hline Total & I,024 eyes & $50.6 \pm 27.7$ & \\
\hline
\end{tabular}

Note: Statistical analysis was performed using Welch's $t$-test. 
to Lincoff's classification. Such cases with unknown details, two detachments in one eye, and 3- or 9-o' clock detachments were included into "cannot be classified or details unclear" groups and involved a total of 152 eyes. In cases with multiple retinal breaks, the most superior break was designated as the original break because it would produce the same contour if it had occurred alone, as mentioned in Lincoff's report. Finally, we studied 747 eyes divided into the eight groups mentioned earlier.

Table 2 summarizes our results from each group by comparing them with those from Lincoff's original report in 1971. In our cases in Groups 1, 2, 3(A), and 3(B), the agreement rates for retinal detachment morphology and the original retinal break were $92 \%$ (172/187 eyes), 86\% (128/148 eyes), $70 \%$ (279/398 eyes), and 89\% (353/398 eyes), respectively. In Groups 1, 2, and 3(A), our current study demonstrated lower agreement rates than those in Lincoff's original report ( $P=0.001,0.012$, and $<0.00001$ using chi-squared test with or without Yate's continuity correction). In Group 3(B), our agreement rates had lower tendency but not significant ( $P=0.067$ using chi-squared test).

In our cases in Groups 4-7, the agreement rates for retinal detachment morphology and the original retinal break were $33 \%$ ( $1 / 3$ eyes), $83 \%$ (45/54 eyes), $100 \%$ (1/1 eye), and $100 \%$ (1/1 eye), respectively. In Group 8, the agreement rate for retinal detachment morphology and the original retinal break was 56\% (9/16 eyes) and much lower than that in Lincoff's original report $(87 \%)(P=0.00085$, using chi-squared test $)$.
We show the median refractive error in temporal or nasal superior detachments, or Group 1 (Figures 1 and 2); in inferior shallow detachment, or Group 2 (Figure 3); and in 12 o'clock detachment, Group 3(B) (Figure 5). Table 3 shows a comparison of corresponding rates between the above $-6 \mathrm{D}$ group and the under $-6 \mathrm{D}$ group. The median refractive error of all patients was $-3.87 \pm 4.28$ D. In Group 1, the median refractive error was $-3.08 \pm 3.66 \mathrm{D}$ and the corresponding rates were $98 \%$ in the above $-6 \mathrm{D}$ group and $100 \%$ in the under -6 D group. In Group 2, the median refractive error was $-5.30 \pm 3.41 \mathrm{D}$ and the corresponding rates were $86 \%$ in the above $-6 \mathrm{D}$ group and $100 \%$ in the under $-6 \mathrm{D}$ group. In Group 3(B), the median refractive error was $-4.31 \pm 4.30 \mathrm{D}$ and the corresponding rates were $94 \%$ in the above $-6 \mathrm{D}$ group and $95 \%$ in the under $-6 \mathrm{D}$ group. There was no significant difference in Groups 1, 2, and 3(B) $(P=0.729,0.065$, and 0.567 using Fisher's exact test or chi-squared test with Yate's continuity correction).

We also show that the number of patients who never underwent cataract surgery or had cataract surgery performed before the rhegmatogenous detachment with or without rupture in Groups 1, 2, and 3(B) in Table 4 and show the agreement rates of each with Lincoff's law. In Group 1, the agreement rates were 93\% for the group who never underwent cataract surgery in this category, $89 \%$ for those who underwent cataract surgery without posterior capsule rupture, and $100 \%$ for those who had posterior capsule rupture. In Group 2, the agreement rates were $87 \%$

Table 2 Corresponding numbers between the original text and our present study

\begin{tabular}{|c|c|c|c|}
\hline & Original text in $\left.197\right|^{14}$ & Our present study & $P$-values \\
\hline Superior temporal or nasal detachments (Group I) (Figures I and 2) & $98 \%(275 / 279$ eyes $)$ & $92 \%$ ( $172 / 187$ eyes $)$ & $P=0.001$ \\
\hline $\begin{array}{l}\text { Inferior shallow detachments } \\
\text { (Group 2) (Figure 3) }\end{array}$ & $95 \%$ ( $145 / 153$ eyes $)$ & $86 \%(128 / 148$ eyes $)$ & $P=0.012$ \\
\hline $\begin{array}{l}\text { Detachments across } 12 \text { o'clock } \\
\text { The original hole was within the triangle whose apex was at I2:00 and intersected } \\
\text { the equators as shown in the schema in the original text (Group 3[A]) (Figure 4) }\end{array}$ & $93 \%$ (3I5/340 eyes) & $70 \%$ (279/398 eyes) & $P<0.0000$ I \\
\hline $\begin{array}{l}\text { Detachments across } 12 \text { o'clock } \\
\text { The original hole was within I I/2 hours of } 12: 00 \text { or from } 10: 30 \text { to } 1: 30 \text { in own } \\
\text { criteria (Group } 3[\mathrm{~B}] \text { ) (Figure } 5 \text { ) }\end{array}$ & $93 \%$ (3I5/340 eyes) & $89 \%$ (353/398 eyes) & $P=0.067$ \\
\hline $\begin{array}{l}\text { Detachments from breaks at } 6 \text { o'clock } \\
\text { (Group 4) (Figure 6) }\end{array}$ & Exact number unknown & $33 \%$ (I/3 eyes) & \\
\hline $\begin{array}{l}\text { Inferior bullous detachments } \\
\text { (Group 5) (Figure 7) }\end{array}$ & Exact number unknown & $83 \%$ (45/54 eyes) & \\
\hline $\begin{array}{l}\text { Across the superior vertical midline and both horizontal midlines (Group 6) } \\
\text { (Figure 8) }\end{array}$ & Exact number unknown & $100 \%$ (I eye) & \\
\hline $\begin{array}{l}\text { Almost total detachment except for a superior wedge-shaped attachment } \\
\text { (Group 7) (Figure 9) }\end{array}$ & Exact number unknown & $100 \%$ (I eye) & \\
\hline $\begin{array}{l}\text { Total detachments } \\
\text { (Group 8) (Figure I0) }\end{array}$ & $106 / 120$ (87\%) & $56 \%$ ( $9 / 16$ eyes $)$ & $P=0.00085$ \\
\hline Cannot be classified or details unclear & - & 152 & \\
\hline Total & 1,000 & $\mathrm{I}, 024$ & \\
\hline
\end{tabular}

Note: Statistical analysis was performed using chi-squared test with or without Yate's continuity correction. 
Table 3 Refractive error in the present study (only phakic eyes and those that never underwent previous cataract surgery; moreover, those in which the macula remained attached before the operation)

\begin{tabular}{|c|c|c|c|c|}
\hline \multirow{3}{*}{$\begin{array}{l}\text { Superior temporal or nasal detachments (Group I) } \\
\text { (Figures I and } 2)(n=70)\end{array}$} & \multirow{3}{*}{$\begin{array}{l}\text { The median refractive } \\
\text { error (D) } \\
-3.08 \pm 3.66\end{array}$} & \multicolumn{2}{|c|}{ The corresponding rate } & \multirow{3}{*}{$\begin{array}{l}P \text {-values } \\
P=0.729\end{array}$} \\
\hline & & $\begin{array}{l}\text { Above }-6 \mathrm{D} \\
(5 \mathrm{I} / 70 \text { eyes) }\end{array}$ & $98 \%$ (50/5I eyes) & \\
\hline & & $\begin{array}{l}\text { Under -6 D } \\
\text { (19/70 eyes) }\end{array}$ & $100 \%$ (19/19 eyes) & \\
\hline \multirow[t]{2}{*}{$\begin{array}{l}\text { Inferior shallow detachments } \\
\text { (Group 2) (Figure 3) }(n=56)\end{array}$} & \multirow[t]{2}{*}{$-5.30 \pm 3.4 I$} & $\begin{array}{l}\text { Above }-6 \text { D } \\
\text { (29/56 eyes) }\end{array}$ & $86 \%$ (25/29 eyes) & \multirow{2}{*}{$P=0.065$} \\
\hline & & $\begin{array}{l}\text { Under -6 D } \\
\text { (27/56 eyes) }\end{array}$ & 100\% (27/27 eyes) & \\
\hline \multirow{2}{*}{$\begin{array}{l}\text { Detachments across } 12 \text { o'clock } \\
(\mathrm{n}=\mathrm{I} 43) \\
\text { (Group 3[B]) (Figure 5) }\end{array}$} & \multirow[t]{2}{*}{$-4.3 I \pm 4.30$} & $\begin{array}{l}\text { Above }-6 \text { D } \\
\text { (10I/143 eyes) }\end{array}$ & 94\% (95/I0I eyes) & \multirow{2}{*}{$P=0.567$} \\
\hline & & $\begin{array}{l}\text { Under -6 D } \\
\text { (42/143 eyes) }\end{array}$ & $95 \%$ (40/42 eyes) & \\
\hline $\begin{array}{l}\text { Total } \\
\text { (only phakic eyes and patients in whom the macula } \\
\text { remained attached) }(n=338)\end{array}$ & $-3.87 \pm 4.28$ & \multicolumn{2}{|c|}{$\begin{array}{l}\text { Above }-6 \text { D } \\
\text { I } 36 \text { of } 338 \text { eyes (only phakic eyes with an attached } \\
\text { macula) Under }-6 D \\
302 \text { of } 338 \text { eyes (only phakic eyes with an attached } \\
\text { macula) }\end{array}$} & \\
\hline
\end{tabular}

Notes: Statistical analysis was performed using Fisher's exact test or chi-squared test with Yate's continuity correction. Group I: superior temporal or nasal detachments. Group 2: inferior shallow detachments. Group 3: detachments intersecting the 12 o'clock superior vertical midline.

for those who never underwent cataract surgery, $87 \%$ for those who underwent surgery without a rupture, and $83 \%$ for those who experienced a rupture. In Group 3, the agreement rates were $89 \%$ for those who never underwent cataract surgery, $97 \%$ for those who underwent surgery without a rupture, and $100 \%$ for those who experienced a rupture. There were no significant differences between those who never underwent cataract surgery, those who underwent surgery without a rupture, and those who experienced a rupture in each group (each $P$-value is shown in Table 4 using Fisher's exact test or the chi-squared test with Yate's continuity correction).

\section{Discussion}

Regarding the locations of breaks and shapes of detachments, in 1972, when both Yoshioka et al and Hanselmayer examined their patients, they partly modified Lincoff's law. Yoshioka et al partially allowed breaks within 2 hours of the superior edge of a temporal or nasal superior detachment, and the corresponding rate was 95\% (92/97 eyes). Moreover, Hanselmayer allowed breaks within 2 hours of the superior edge and the corresponding rate was $93 \%$ (156/168 eyes), although it was 57\% (96/168 eyes) within 1 hour of the superior edge in this category. Regarding inferior detachments, Yoshioka et al examined original breaks within 2 hours around

Table 4 Previous cataract surgery before rhegmatogenous retinal detachment and agreement rates

\begin{tabular}{|c|c|c|c|c|}
\hline \multirow{4}{*}{$\begin{array}{l}\text { Superior temporal or nasal } \\
\text { detachments (Group I) } \\
\text { (Figures I and 2) }\end{array}$} & \multirow{2}{*}{$\begin{array}{l}\text { Previous cataract surgery } \\
\text { Phakic (never underwent cataract surgery } \\
\text { before the operation) }\end{array}$} & \multirow{2}{*}{$\begin{array}{l}\text { Agreement rate } \\
93 \%(142 / 153 \text { eyes })\end{array}$} & \multicolumn{2}{|l|}{$P$-values } \\
\hline & & & \multirow{3}{*}{$\begin{array}{l}] \\
] \\
70.902-\end{array}$} & \multirow{3}{*}{0.746} \\
\hline & $\begin{array}{l}\text { Eyes that previously underwent cataract } \\
\text { surgery without posterior capsule rupture }\end{array}$ & $89 \%$ ( $16 / 18$ eyes $)$ & & \\
\hline & With posterior capsule rupture or aphakia & $100 \%$ (4/4 eyes) & & \\
\hline \multirow{3}{*}{$\begin{array}{l}\text { Inferior shallow detachments } \\
\text { (Group 2) (Figure 3) }\end{array}$} & Phakic & $87 \%$ (I08/I24 eyes) & \multirow{2}{*}{0.726} & \multirow{3}{*}{0.576} \\
\hline & $\begin{array}{l}\text { Underwent cataract surgery without } \\
\text { rupture }\end{array}$ & $87 \%$ (7/8 eyes) & & \\
\hline & Rupture or aphakia & $83 \%$ (5/6 eyes) & 0.69 & \\
\hline \multirow[t]{3}{*}{$\begin{array}{l}\text { Detachments across } 12 \text { o'clock } \\
\text { (Group 3[B]) (Figure 5) }\end{array}$} & $\begin{array}{l}\text { Phakic (never underwent cataract surgery } \\
\text { before the operation) }\end{array}$ & $89 \%$ (30I/338 eyes) & \multirow{3}{*}{$\left.\begin{array}{l}0.211 \\
0.837\end{array}\right]$} & \multirow{3}{*}{0.757} \\
\hline & $\begin{array}{l}\text { Underwent cataract surgery without } \\
\text { rupture }\end{array}$ & $97 \%$ (35/36 eyes) & & \\
\hline & Rupture or aphakia & $100 \%$ (7/7 eyes) & & \\
\hline
\end{tabular}

Notes: Statistical analyses were performed using Fisher's exact test or chi-squared test with Yate's continuity correction. Group I: superior temporal or nasal detachments. Group 2: inferior shallow detachments. Group 3: detachments intersecting the 12 o'clock superior vertical midline. 
$1 / 2$ hour below the superior edge, and the corresponding rate was $92 \%$ (60/65 eyes). Hanselmayer examined breaks within 2 hours from the midline of detachment, and the corresponding rate was $80 \%$ (59/74 eyes), although it was $62 \%$ (46/74 eyes) within 1 hour. Regarding detachments across 12 o'clock, Yoshioka et al examined breaks within 1 hour of $11: 30$ or $12: 30$, or within $11 / 2$ hours of $11: 30$ or $12: 30$, or within $1 / 2$ hour of 12 o'clock, or between 11:00 and 1:30; each law was applied according to more detailed classifications of their own in this category and was added to $92.8 \%$ (142/153 eyes). Hanselmayer allowed breaks within 2 hours of 12 o'clock, and the corresponding rate was $77 \%$ (108/140 eyes), although it was $69.2 \%$ (97/140 eyes) within 1 hour of 12 o'clock. These studies are shown in Table 5. Moreover, our study is the first experiment investigating Lincoff's law while strictly following his original definition to our best knowledge.

Later studies seem to have lower agreement rates than those in Lincoff's original report. One of the reasons for which this is notable is that the original report had especially high agreement rates. We considered that retinal detachments develop mainly from gravity, although a certain proportion of detachments were present, which had strong tractions or posterior breaks that deviated from Lincoff's law. Perhaps the rates of the patients in the present study were higher than those of Lincoff's subjects.

Concerning our study, our patients were almost all singlerace Japanese and the Japanese population was reported to contain a higher ratio of myopic patients. ${ }^{21}$ Lincoff did not mention refractive errors in the original report. However, myopic patients have a long axial length and often have lattice degeneration, which can cause multiple breaks with wide vitreous traction. Thus, we examined whether traction caused by myopia could perhaps allow the progression of detachments that did not proceed solely due to gravity. Although the study was limited to only patients who were identified as having never undergone cataract surgery before and who had an attached macula, the refractive errors of patients in our study demonstrated no higher myopic refractive error (mean, $-3.87 \pm 4.28 \mathrm{D}$ ) than previously reported refractive errors in rhegmatogenous detachments $\left(-5.5 \mathrm{D}^{28}\right.$ and $-5.0 \mathrm{D}^{29}$ in the UK and under $-6 \mathrm{D}^{30}$ in the USA), though there is a high ratio of myopic eyes in the Japanese relative to other races in healthy subjects. ${ }^{21}$ This discussion has the limitation that these previous reports were about round-hole retinal detachments, roughly corresponding to Group 2 in our study. In Group 2, the mean refractive error was $-5.3 \mathrm{D}$; nevertheless, it was not much higher than those described previously. Moreover, the agreement rate comparisons between the above $-6 \mathrm{D}$ detachment group and under $-6 \mathrm{D}$ detachment group were not significantly different in Groups 1, 2, or 3(B). According to this finding, we considered that as high myopia progresses, the ratio of rhegmatogenous detachment increases equally despite differences in race and there was not much of a refractive difference between races among patients with rhegmatogenous detachment. Therefore, we consider our lower agreement rates than Lincoff's could be influenced by deviated situations that had strong tractions or posterior breaks but that these situations were independent from the Japanese myopic ratio. However, there was the limitation that our data could not exclude the possibility that patients who had a detached fovea had greater myopia and greater abnormal traction.

Lincoff reported on aphakic or pseudophakic detachment in other studies..$^{23,24}$ It is assumed that Lincoff's original law did not include subjects who underwent cataract surgery because intracapsular cataract extraction was popular in those days. Our study contains subjects who underwent cataract surgery. Furthermore, we included 31 subjects with

Table $\mathbf{5}$ The results of previous studies according to Lincoff's report

\begin{tabular}{|c|c|c|}
\hline & Yoshioka et al ${ }^{19}$ & Hanselmayer ${ }^{20}$ \\
\hline $\begin{array}{l}\text { Temporal or nasal superior } \\
\text { detachment }\end{array}$ & $\begin{array}{l}\text { Partially allowed within } 2 \text { hours } \\
95 \% \text { (92/97 eyes) }\end{array}$ & $\begin{array}{l}\text { Within } 2 \text { hours } \\
93 \%(156 / 158 \text { eyes }) \\
\text { Within I hour } \\
57 \%(96 / 158 \text { eyes })\end{array}$ \\
\hline Inferior detachment & $\begin{array}{l}\text { Within } 2 \text { hours around the } 1 / 2 \text { hour below } \\
\text { the superior edge } \\
92 \%(60 / 65 \text { eyes })\end{array}$ & $\begin{array}{l}\text { Within } 2 \text { hours of the midline } \\
\text { of detachments } \\
80 \% \text { ( } 59 / 74 \text { eyes }) \\
\text { Within I hour } \\
62 \% \text { ( } 46 / 74 \text { eyes) }\end{array}$ \\
\hline Detachment across 12 o'clock & $\begin{array}{l}\text { Within I o'clock from II:30 or 12:30, or within } \\
\text { I I/2 hours from II:30 or 12:30, or I/2 hour } \\
\text { from I2 o'clock, or between II:00 and I:30 } \\
92.8 \% \text { (142/I53 eyes) }\end{array}$ & $\begin{array}{l}\text { Within } 2 \text { hours from } 12 \text { o'clock } \\
77 \% \text { ( } 108 / 140 \text { eyes }) \\
\text { Within I hour from } 12 \text { o'clock } \\
69 \% \text { ( } 97 / / 40 \text { eyes })\end{array}$ \\
\hline
\end{tabular}


a ruptured posterior capsule and six aphakic subjects. It is well known that posterior vitreous detachment progresses after cataract surgery ${ }^{25}$ and posterior vitreous detachment is an important factor in the formation of retinal breaks. ${ }^{26}$ Especially, a ruptured posterior capsule induces vitreous extraction into the anterior chamber and abnormal vitreous traction. ${ }^{27}$ There was the possibility that these subjects included in our study after cataract surgery influenced the lower agreement rates. However, throughout examining the agreement ratios in subjects with ruptures, there were few subjects in whom the detachment exceeded Lincoff's law, as shown in Table 4. Therefore, we consider that our lower agreement rate than shown by Lincoff could have been influenced by deviated subjects that had strong tractions or posterior breaks; however, these situations did not increase according to protruded vitreous with rupture, or to the higher proportion of myopia in the Japanese population. Although subjects with ruptures showed different tendency regarding the break locations, ${ }^{24}$ compared to subjects with phakia, each gravity working on the flow of subretinal fluid followed Lincoff's law and abnormal vitreous traction caused by protruded vitreous did not come out to the surface.

Especially, the number of total detachments (Group 8) was 16 eyes and very small relative to that in Lincoff's report of 120 eyes. This explains the shorter period between onset and surgery in this study. This is because retinal detachment has become a well-known disease that is now correctly diagnosed and surgical techniques have progressed such that the operation can be performed safely. Moreover, the agreement rate in this category was much lower than that in our study. Perhaps it is notable that total detachments were affected not only by gravity but also by the strong vitreous traction in each eye; this tendency is accurate in the early phase before gravity has had more time to form the detachment shape in the late phase. Therefore, we consider that total detachments seen in the present study had been completed within much shorter periods and included a higher ratio of outlier cases, with strong vitreous tractions. In contrast, total detachments in Lincoff's study had been completed slowly with gravity, including various forms of detachments in other categories, and had increased in number to some extent.

Regarding multiple inferior breaks across 6 o'clock, it is sometimes difficult to determine the most superior break, which can lead to a lower agreement rate. Moreover, regarding the agreement rate at detachments beyond 12 o'clock in our study, the ratio of the holes appearing $11 / 2$ hours from 12 o'clock (Figure 5) was higher than the ratio of holes appearing within the triangle (Figure 4) in Lincoff's schema.
It is considered that $11 / 2$ hours from 12 o'clock is more appropriate to use than within the triangle in this category, especially in Japanese patients.

The current study has several limitations. Though all medical records and detachment charts examined were independently drawn by several observers, there were 152 detachments that could not be classified into an established category because this was a retrospective study. In contrast, Lincoff classified all subjects into his categories. Furthermore, an accurate refractive error was only identified for patients who had never undergone cataract surgery before and whose macula had remained attached. Moreover, we did not examine refractive error in Groups 4- 8 because of the small numbers of identified subjects. There was the possibility that patients who had a detached fovea had greater myopia, as stated before, and perhaps especially in total detachment. Additionally, the interval between onset and surgery was not examined. We need further prospective experience to determine the break's location, refractive error, axial length, and the onset of detachment before surgery for more exact observations.

\section{Conclusion}

Lincoff's law was suitable for the present cases and Japanese cases and was almost independent of refractive error and previous cataract surgery. However, agreement rates were lower than in the original report, especially for total detachments. Within $11 / 2$ hours from 12 o' clock was more adequate for the corresponding break region than within a triangle whose apex is at 12 o'clock and intersecting the equators in detachments across 12 o'clock.

\section{Acknowledgments}

There was no sponsorship or other support for this study. We had no statistical consultation or assistance. We would like to thank Editage (www.editage.jp $)$ for English language editing.

\section{Author contributions}

All authors contributed toward data analysis, drafting and revising the paper and agree to be accountable for all aspects of the work.

\section{Disclosure}

The authors report no conflicts of interest in this work.

\section{References}

1. Schepens CL. Scleral buckling procedures. Trans Am Acad Ophthalmol Otolaryngol. 1958;62:206-218. 
2. Michels RG. Scleral buckling methods for rhegmatogenous retinal detachment. Retina. 1986;6(1):1-49.

3. Lincoff HA, Baras I, McLean J. Modifications to the Custodis procedure for retinal detachment. Arch Ophthalmol. 1965;73:160-163.

4. Lincoff HA, Kreissig I, Hahn YS. A temporary balloon buckle for the treatment of small retinal detachments. Ophthalmology. 1979; 86(4):586-596.

5. Noori J, Bilonick RA, Eller AW. Scleral buckle surgery for primary retinal detachment without posterior vitreous detachment. Retina. 2016;36(11):2066-2071.

6. Escoffery RF, Olk RJ, Grand MG, Boniuk I. Vitrectomy without scleral buckling for primary rhegmatogenous retinal detachment. Am J Ophthalmol. 1985;99(3):275-281.

7. Brazitikos PD. The expanding role of primary pars plana vitrectomy in the treatment of rhegmatogenous noncomplicated retinal detachment. Semin Ophthalmol. 2000;15(2):65-77.

8. Bonnet M. Indications de vitrectomie dans le traitement du décollement rhegmatogène de la rétine. [Indications of vitrectomy in the treatment of rhegmatogenous detachment of the retina]. Ophtalmologie. 1987;1(1):95-100. French.

9. Tomita Y, Kurihara T, Uchida A, et al. Wide-angle viewing system versus conventional indirect ophthalmoscopy for scleral buckling. Sci Rep. 2015;5:13256.

10. Aras C, Ucar D, Koytak A, Yetik H. Scleral buckling with a noncontact wide-angle viewing system. Ophthalmologica. 2012;227(2): $107-110$.

11. Kunikata H, Nishida K. Visual outcome and complications of 25-gauge vitrectomy for rhegmatogenous retinal detachment; 84 consecutive cases. Eye (Lond). 2010;24(6):1071-1077.

12. Xia F, Jiang YQ. Clinical outcomes of 23-gauge vitrectomy may be better than 20-gauge vitrectomy for retinal detachment repair. Mol Vis. 2015;21:893-900.

13. Von Fricken MA, Kunjukunju N, Weber C, Ko G. 25-Gauge sutureless vitrectomy versus 20 -gauge vitrectomy for the repair of primary rhegmatogenous retinal detachment. Retina. 2009;29(4):444-450.

14. Lincoff H, Gieser R. Finding the retinal hole. Arch Ophthalmol. 1971; 85(5):565-569.

15. Saxena $S$, Lincoff $H$. Finding the retinal break in rhegmatogenous retinal detachment. Indian J Ophthalmol. 2001;49(3):199-202.

16. Ogino N. [Refraction and age distribution of hole type retinal detachment (author's transl)]. Nippon Ganka Gakkai Zasshi. 1980;84(11): 2027-2030. Japanese.

17. Okinami S, Ogino N, Nishimura T, Tano Y. Juvenile retinal detachment. Ophthalmologica. 1987;194(2-3):95-102.
18. Hirata A, Okinami S. [Clinical features and prognosis of retinal detachment with retinal breaks located posterior to the equator]. Nippon Ganka Gakkai Zasshi. 1985;89(7):860-864. Japanese.

19. Yoshioka H, Sugita T, Nakano M. [The relation between the shape of detached retina and the position of the hole in retina]. Nippon Ganka Gakkai Zasshi. 1972;76(6):365-370. Japanese.

20. Hanselmayer H. Lokalisierung von Defekten in Bezug auf das Ausmaß von Netzhautablösungen. [Localization of defects in relation to the extent of retinal detachments]. Klin Monbl Augenheilkd. 1972;161(5):510-515. German.

21. Shimizu N, Nomura H, Ando F, Niino N, Miyake Y, Shimokata H. Refractive errors and factors associated with myopia in an adult Japanese population. Jpn J Ophthalmol. 2003;47(1):6-12.

22. Di Lauro S, Kadhim MR, Charteris DG, Pastor JC. Classifications for proliferative vitreoretinopathy (PVR): an analysis of their use in publications over the last 15 years. $J$ Ophthalmol. 2016;2016:7807596.

23. Lincoff H, Kreissig I, Farber M. Results of 100 aphakic detachments treated with a temporary balloon buckle: a case against routine encircling operations. Br J Ophthalmol. 1985;69(11):798-804.

24. Lincoff H, Kreissig I. Finding the retinal hole in the pseudophakic eye with detachment. Am J Ophthalmol. 1994;117(4):442-446.

25. Degirmenci C, Afrashi F, Mentes J, Oztas Z, Nalcaci S, Akkin C. Evaluation of posterior vitreous detachment after uneventful phacoemulsification surgery by optical coherence tomography and ultrasonography. Clin Exp Optom. 2017;100(1):49-53.

26. Ripandelli G, Coppé AM, Parisi V, et al. Posterior vitreous detachment and retinal detachment after cataract surgery. Ophthalmology. 2007; 114(4):692-697.

27. Petousis V, Sallam AA, Haynes RJ, et al. Risk factors for retinal detachment following cataract surgery: the impact of posterior capsular rupture. Br J Ophthalmol. 2016;100(11):1461-1465.

28. Williams KM, Dogramaci M, Williamson TH. Retrospective study of rhegmatogenous retinal detachments secondary to round retinal holes. Eur J Ophthalmol. 2012;22(4):635-640.

29. Ung T, Comer MB, Ang AJ, et al. Clinical features and surgical management of retinal detachment secondary to round retinal holes. Eye (Lond). 2005;19(6):665-669.

30. Gonzales CR, Gupta A, Schwartz SD, Kreiger AE. The fellow eye of patients with phakic rhegmatogenous retinal detachment from atrophic holes of lattice degeneration without posterior vitreous detachment. Br J Ophthalmol. 2004;88(11):1400-1402.
Clinical Ophthalmology

\section{Publish your work in this journal}

Clinical Ophthalmology is an international, peer-reviewed journal covering all subspecialties within ophthalmology. Key topics include: Optometry; Visual science; Pharmacology and drug therapy in eye diseases; Basic Sciences; Primary and Secondary eye care; Patient Safety and Quality of Care Improvements. This journal is indexed on Submit your manuscript here: http://www.dovepress.com/clinical-ophthalmology-journal

\section{Dovepress}

PubMed Central and CAS, and is the official journal of The Society of Clinical Ophthalmology (SCO). The manuscript management system is completely online and includes a very quick and fair peer-review system, which is all easy to use. Visit http://www.dovepress.com/ testimonials.php to read real quotes from published authors. 